\title{
The Impact of UCP600 on the Practical Teaching of International Trade Major and the Countermeasure to Cope With It
}

\author{
Li Junfeng , Meng Fanhua
}

Management Department North China Institute of Science and Technology Yanjiao (Beijing-East), China

\begin{abstract}
The practical teaching is an important teaching process in professional education plan of international trade major. The pactice of L/C (letter of credit) settlement transaction is important content of practical teaching. The implementation of UCP600 brings new requirements for the credit business operation. About the new rules, we must make some adjustment in practical teaching of international trade in time. The paper analyzes the new changes of UCP600 comparing to UCP500, then analyzes the existing problems of international trade practical teaching. In final, the paper puts forward the countermeasures to cope with UCP600.
\end{abstract}

Index Terms: International trade; Practical teaching; UCP600

(C) 2012 Published by MECS Publisher. Selection and/or peer review under responsibility of the International Conference on E-Business System and Education Technology

\section{Introduction}

The practical teaching is an important teaching process in professional education plan of international trade. It is an important approach to improve students' comprehensive quality and practical operation skills of international trade. At present, the $\mathrm{L} / \mathrm{C}$ is the most important settlement method in international settlement field, so $\mathrm{L} / \mathrm{C}$ business training is important content of practical teaching. There are many new requirements and criteria in the operation of L/C business with the implementation of UCP600--latest practice of the documentary credit. Compared with UCP500, new consuetude puts forward new requirements to banks, importers and exporters. About the new rules, practical teaching of international trade must be adjusted and adapt to the new situation and change, conforming to the new international standard.

\section{New regulations of UCP600 to credit settlement business}

\subsection{The new regulations on opening and amendment of $L / C[1]$}

1) New regulations on opening of L/C. In the article 2 (definition) and article 3 (interpretation) in UCP600, there are clauses stipulating that the credit is irrevocable even if there is no indication to that effect. This suggests

Corresponding author:

E-mail address: 
that UCP600 deleted article 6 of "revocable and irrevocable credits" under UCP500, emphasizing the L/C opened under UCP600 is irrevocable [7].

2) New regulations on amendment of L/C. The sub-article 10 (C) of UCP600 regulates: "The beneficiary should give notification of acceptance or rejection of an amendment. If the beneficiary fails to give such notification, a presentation that complies with the credit and to any not yet accepted amendment will be deemed to be notification of acceptance by the beneficiary of such amendment. As of that moment the credit will be amended." UCP600 adds the words: "A provision in an amendment to the effect that the amendment shall enter into force unless rejected by the beneficiary within a certain time shall be disregarded." This clause avoids possibility of the "automatic effect" [3].

\subsection{The new regulations on presentation of documents under $L / C$}

1) The new regulations of time of presentation documents. The article 6 of UCP600 regulates: "A credit must state an expiry date for presentation. An expiry date stated for honour or negotiation will be deemed to be an expiry date for presentation; Except as provided in sub-article 29 (a), a presentation by or on behalf of the beneficiary must be made on or before the expiry date.” The sub-article 14 (C) of UCP600 regulates: "A presentation including one or more original transport documents subject to articles 19, 20, 21, 22, 23, 24 or 25 must be made by or on behalf of the beneficiary not later than 21 calendar days after the date of shipment as described in these rules, but in any event not later than the expiry date of the credit.” That is to say, as long as there are transport documents in document list, even if the credit provides longer presentation period and the validity, the exporter must present documents to the bank not later than 21 calendar days after the date of shipment [8]. The 21 days refers to the natural day, while non-banking business days [4].

2) The new regulations of location of presentation documents. The article 6 of UCP600 regulates: "The place of the bank with which the credit is available is the place for presentation. The place for presentation under a credit available with any bank is that of any bank. A place for presentation other than that of the issuing bank is in addition to the place of the issuing bank.” That is to say, if the exporter in the $\mathrm{L} / \mathrm{C}$ can't find a bank to negotiate or to send documents in stipulated place, he can send the documents to the issuing bank directly, or go to issuing bank counter to present documents [9].

\subsection{The new regulations on examination of documents and dishonor under $L / C$}

1) The new regulations of examination of documents. First, UCP600 regulates definitely: "nominated banks acting on its nomination, a confirming bank, if any, and the issuing bank shall each have a maximum of five banking days following the day of presentation to determine if a presentation is complying." Compared with the clause in UCP500, UCP600 shorten the time of examination of documents clearly. Secondly, UCP600 puts forward new standard for examination of documents in article 14 and 15. It says: "Data in a document, when read in context with the credit, the document itself and international standard banking practice, need not be identical to, but must not conflict with, data in that document, any other stipulated document or the credit." So, UCP600 emphasize that document must meet its function, and abandon the principle of "strict compliance" in UCP500. [2]

2) The new regulations on dishonor. UCP600 increases bank's methods of disposal to documents when they are dishonored in sub-article 16 (C). That is as follows: "holding the documents pending further instructions from the presenter", "holding the documents until it receives a waiver from the applicant and agrees to accept it", "returning the documents", and "acting in accordance with instructions previously received from the presenter". This adjustment conforms to the actual needs of the business, and reduces the possibility of disputes between parties under L/C [5]. 


\subsection{The new regulations on transfer of $L / C$}

Under UCP600, the biggest modification about transferable credit is embodied in sub-article 38(i). That says: "If the first beneficiary is to present its own invoice and draft, if any, but fails to do so on first demand, or if the invoices presented by the first beneficiary create discrepancies that did not exist in the presentation made by the second beneficiary and the first beneficiary fails to correct them on first demand, the transferring bank has the right to present the documents as received from the second beneficiary to the issuing bank, without further responsibility to the first beneficiary.” This new clause protects the second beneficiary without fault [6].

\section{Problems in international trade practical teaching under UCP600}

For the time isn't very long after UCP600 had become effective, there are still many traces of UCP500 on current international trade practical teaching at present. Practical teaching has not yet been fully implemented the transition from UCP500 to UCP600.

\section{1 The content of teaching material about L/C haven't been fully updated according to UCP600.}

Most textbooks just introduce UCP600 briefly, haven't put it into specific process of credit settlement. For example, when introducing the types of L/C, many textbooks just simply explains that the revocable $\mathrm{L} / \mathrm{C}$ is eliminated under UCP600, while not explains the tiny change on different types of credit in detail. For example, there isn't specific explaination about the change of parties' responsibility under transferable L/C, so it still need teacher to make a supplement. In addition, relevant outline and instruction book of practical classes also need urgently to be revised or rebuilt according to UCP600 [10].

3. 2 The teachers of practical teaching can't understand veritably about the clauses of UCP600 for they have not received the system training about it.

UCP600 is revised by the senior experts organized by the international chamber of commerce spenting many years, reflects new situation and new problem of the global credit settlement in recent years, includes many professional and technical term. Many clauses in UCP600 are very obscure and ambiguous in grammar. In addition, most teachers are lack of actual work experience on credit transactions that lead to failure of conforming to the latest practice when teaching the $\mathrm{L} / \mathrm{C}$ operation.

3. 3 Most software equipments of practical teaching, developed under UCP500, fail to update or upgrade in time, and some practical procedures and template under the old rules can't satisfy the requirement of the new practice operation.

Many practical courses of international trade major are based on simulation in laboratory, most of which are about credit settlement business. Doing these experiments, students need to download a large number of documents template from software, while materials provided by experiments of software are in accordance with UCP500, which makes a negative effect of weakening theory teaching.

3. 4 The form of practical teaching is relatively single, and the new requirement of UCP600 can't be practised in practical teaching, making knowledge system of practical teaching non-comprehensive.

For example, the risk of relevant parties appeares some new changes under UCP600, but these changes haven't almost been reflected in the practical curriculum system. For another example, there are new regulations on examination of documents such as time and standard of examination, but the original training form can not 
simulate such new changes. While, it is especially important that students grasp these new changes in the new international practice.

\section{The countermeasures to cope with UCP600 in practical teaching}

Based on analysis of the current problems in international trade practical teaching, the current practice teaching methods and content all need to make great adjustment in order to adapt UCP600's requirement. Finding countermeasure to cope with it determines whether the education goal can be realized and concern student's employment in the future.

\section{1 Update contents of teaching material according to UCP600}

An excellent textbook can make teaching get maximum achievement with little effort. The teachers of specialty should edit or revise practice guidance materials and textbooks. Editing teaching material is a systemic project, need cooperation and assistance of every aspect. In the process of editing, we should absorb the latest research results about UCP600 and essence of current textbooks. We should organize the students and teachers making discussion and exchanging opinions, striving to make teaching materials edited satisfy the new practice operation requirement.

\section{2 Strengthen training and study for teachers, grasp new regulations of UCP600}

As a reference, the staffs of banks' international settlement department had widely been trained at the beginning of implementation of UCP600. Teachers teaching practice should also use all sorts of the opportunity to participate relevant professional training or seminars about UCP600. Through training and seminars, they can solve some theoretical problems puzzling them for long time, and in these situations, the teachers can also contact with practitioners in international trade field, and obtain some real material in real business. In addition, we can also call back some graduated students to school to introduce new practice of L/C with real cases.

\section{3 Improve the software and hardware conditions of practical teaching to meet the new requirement of UCP600}

Combining the current specific courses, in general, there are some practical courses named "comprehensive experiment of foreign trade documentaries" or "simulation training of foreign trade" in major education plan. The software used in these courses is developed under UCP500 for long time. Failing to update it, the teacher can only give students some special instructions and specification to adapt to UCP600 as far as possible in teaching credit transactions. To resolve this problem completely, we need to contact the researcher and manufacturers to upgrade the software or buy new software to adapt to the new rules. If we choose to buy the software, we should pay attention to whether the manufacturer or researcher of software has a promise to upgrade it in time.

\section{4 Break through tradition training form, practise new regulations of UCP600}

Most practical courses of international trade major are carried out in laboratory, but network environment cannot completely simulate some important content in L/C operation such as risks of the parties and endorsement act of instrument. It is very necessary to explore new practical form. To solve this problem, the most effective way is to establish the practice base in foreign trade company. But it will be difficult to build a practice base that can accommodate mass students because the school and company are not easy to get an agreement on problems about practice places, practice time, practice mode and so on. In order to change this situation, teachers should participate actively in contacting practice base, and strive to set up a number of practice bases which has reasonable location in a short time. In addition, we can also use printed documents to 
supplement the software platform. For example, students may make paper draft to exercise bill's acts such as endorsement, acceptance, guarantee, and payment, etc.

\section{Conclusion}

In a word, about UCP600, practical teaching of international trade needs to be adjusted from macroscopical to microcosmic. The paper just puts forward the preliminary scheme and suggestions. While, behind the scheme and suggestions, specific work such as edit of teaching material is quite heavy and challenging, the work of interpretation and translation is even quite boring. When considering it is important and urgent for students to grasp the basic knowledge, we will have a firm belief to make the greatest efforts to accomplish this work.

\section{References}

[1] The Uniform Customs and Practice for Documentary Credits, 2007 Revision, ICC Publication No. 600.

[2] The Uniform Customs and Practice for Documentary Credits, 1993 Revision, ICC Publication No. 500.

[3] Donald R. Smith, What Happened When July 1 UCP600 Rules Took Effect? Managing Imports \& Exports, 2007

[4] Janet Ulph, The UCP600 : Documentary Credits in the Twenty-first Century, The Journal of Business Law, 2007(6)

[5] Ebenezer Adodo, Non-documentary Requirements in Letters of Credit Transactions : What is the Bank's Obligation Today? The Journal of Business Law, 2008(2)

[6] Deborah Horowitz, Banco Santander and the UCP 600, The Journal of Business Law, 2008(6)

[7] Wei Songfeng, Analysis of UCP600 compared with UCP500, Popular Business, 2010 (2). (In Chinese)

[8] Li Xiaoyuan, Time Limit of Document Examination Under UCP600, Journal of Northwest A\&F University (SocialScience Edition), 2010(1). (In Chinese)

[9] Shen Lei, Gao Xiaoyu, On the Presentation and Examination of Documents under UCP600, Journal of Shaanxi Administration School, 2009(2). (In Chinese)

[10] Lou Yu, Effect of UCP600 on International Trade Practice, Journal of Hebei Unerversity of Economics and Trade, 2007(3). (In Chinese) 